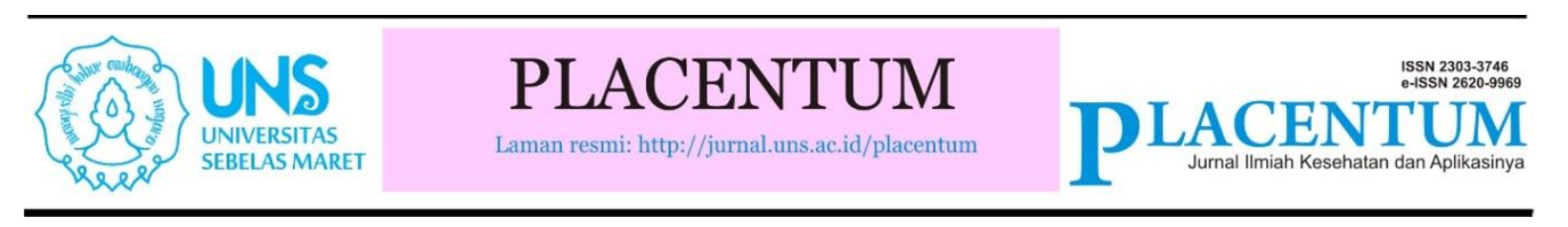

\title{
HUBUNGAN BERAT BADAN DAN TEKANAN DARAH PADA LANSIA
}

\section{Relationship between Weight and Blood Pressure in Elderly \\ Angesti Nugraheni, Sri Mulyani, Erindra Budi Cahyanto Mujahidatul Musfiroh, Ika Sumiyarsi}

Prodi Kebidanan Program Sarjana Terapan Universitas Sebelas Maret email: angestinugraheni.88@gmail.com

\begin{abstract}
ABSTRAK
Latar Belakang: Aktivitas fisik yang dilakukan pada lansia cenderung berkurang, hal ini mengurangi pengeluaran energi untuk metabolisme lemak sehingga menyebabkan kelebihan berat badan dan berakibat otot jantung bekerja lebih keras. Aliran melalui pembuluh darah yang berkurang elastisitasnya menyebabkan jantung bekerja lebih keras sehingga tekanan darah meningkat Tujuan dari penelitian ini adalah untuk mengetahui pengaruh berat badan terhadap tekanan darah pada lansia.

Metode: Desain penelitian menggunakan observasional analitik dengan pendekatan cross sectional. Penelitian akan dilaksanakan pada Januari-Mei 2019 di wilayah Kelurahan Sumber. Sampel penelitian diambil dengan teknik purposive sampling, yang memenuhi kriteria retriksi sejumlah 40 responden. Instrumen penelitian menggunakan timbangan berat badan digital dan tensimeter raksa yang telah dikalibrasi. Analisis data menggunakan uji korelasi spearman.

Hasil: Penelitian menunjukan bahwa berat badan lansia mayoritas dalam kategori kelebihan berat badan tingkat berat yaitu sebanyak 32 (80\%), tekanan darah lansia mayoritas dalam kategori hipertensi (HT derajat I-III) yaitu sebanyak 21 (52.5\%). Hasil uji analisis korelasi spearman menunjukan bahwa terdapat hubungan yang signifikan antara berat badan dan tekanan darah lansia dengan nilai $r 0.401, p=0.01(<0.05)$.

Kesimpulan: Terdapat hubungan yang signifikan antara berat badan dan tekanan darah lansia.
\end{abstract}

Kata Kunci: Lansia, Tekanan darah, Hipertensi. 


\begin{abstract}
Background: Physical activity undertaken in the elderly tends to decrease, this reduces energy expenditure for fat metabolism so that it causes overweight and results in the heart muscle working harder. The flow through the blood vessels which decreases elasticity causes the heart to work harder so that blood pressure increases. The purpose of this study is to determine the effect of body weight on blood pressure in the elderly.

Method: The study design used observational analytics with a cross sectional approach. The research will be conducted in January - May 2019 in the Sumber Kelurahan area. The research sample was taken by purposive sampling technique, which met the criteria of retention of 40 respondents. The research instrument used a calibrated calibrated digital weighing scale and tensimeter. Data were analyzed using spearman correlation test.

Results: The results showed that the majority of elderly body weight in the category of overweight at the weight level was as much as 32 (80\%), the majority of elderly blood pressure in the hypertension category (HT degree I-III) as many as 21 (52.5\%). The results of the analysis showed that there was a significant relationship between body weight and blood pressure of the elderly with a value of $r 0.401, p=0.01(<0.05)$.

Conclusion: There was a significant relationship between body weight and blood pressure of the elderly.
\end{abstract}

Keyword: Elderly, Blood pressure, hypertension.

\begin{tabular}{l}
\hline \multicolumn{3}{c}{ PENDAHULUAN } \\
\hline Tekanan darah adalah kekuatan yang \\
dihasilkan dinding arteri dengan \\
memompa darah dari jantung. Darah \\
mengalir karena adanya perubahan tekanan \\
dimana terjadi perpindahan dari area \\
bertekanan tinggi ke area bertekanan \\
rendah. Tekanan darah sistemik atau \\
arterial merupakan indikator paling baik \\
untuk kesehatan kardiovaskular ${ }^{11]}$. \\
Peningkatan tekanan darah yang \\
berlangsung dalam jangka waktu lama \\
(persisten) dapat menimbulkan kerusakan \\
pada ginjal (gagal ginjal), jantung \\
(penyakit jantung koroner), dan otak \\
(menyebabkan stroke) bila tidak terdeteksi \\
secara dini serta mendapat pengobatan \\
yang memadai ${ }^{[2]}$. \\
Aktivitas fisik yang dilakukan oleh \\
lansia mulai berkurang atau terbatas, hal \\
ini akan mengurangi pengeluaran energi \\
untuk metabolisme lemak sehingga \\
menyebabkan kelebihan berat badan dan \\
berakibat otot jantung bekerja lebih keras \\
untuk memompa darah dalam jumlah yang \\
sama ke seluruh tubuh. Maka dari itu \\
tekanan darah erat kaitanya dengan berat \\
badan lansia.
\end{tabular}

WHO memperkirakan peningkatan usia harapan hidup pada tahun 2025 jumlah lanjut usia (lansia) akan meningkat dua kali lipat dan pada tahun 2050 akan mencapai 2 miliar secara global. Hasil proyeksi penduduk 2010-2035 menurut data Kementrian Kesehatan Indonesia tahun 2015, Indonesia akan memasuki periode lansia (ageing) di tahun 2020. Tercatat sebanyak 21.685.326 penduduk atau sekitar 8, 49\% dari total penduduk Indonesia adalah lansia. Jawa Tengah merupakan provinsi dengan persentase jumlah lansia terbanyak kedua yaitu sekitar $11,8 \%$ dari total lansia eluruh Indonesia $^{[3]}$.

Data Dinas Kesehatan Surakarta tahun 2016, menunjukan jumlah lansia dengan indeks masa tubuh lebih terbanyak di wilayah Kelurahan Sumber yaitu 124 lansia. Hasil studi pendahuluan yang dilaksanakan pada 5 RW di Kelurahan Sumber didapatkan hasil 13 lansia dengan kelebihan berat badan, 1 lansia di antaranya mengalami hipertensi derajat 3 , 1 lansia mengalami hipertensi derajat 2, 5 lansia mengalami hipertensi derajat 1,2 lansia megalami pre hipertensi, dan 4 
lansia dengan tekanan darah normal. Berdasarkan data tersebut peneliti tertarik untuk melakukan penelitian tentang pengaruh tekanan darah dengan berat badan lansia di Kelurahan Sumber.

\section{SUBJEK DAN METODE}

Tempat penelitian di wilayah Kelurahan Sumber pada bulan Januari - Mei 2019. Penelitian ini menggunakan desain observasional analitik dengan pendekatan cross sectional. Populasi dalam penelitian ini adalah semua lansia di Kelurahan Sumber. Sampel dalam penelitian ini adalah sebagian lansia dengan kriteria restriksi (kelebihan berat badan dan sehat atau tidak sedang menderita penyakit apapun). Teknik pengambilan sampel menggunakan purposive sampling sejumlah 40 responden. Instrumen yang digunakan dalam penelitian ini adalah lembar observasi berat badan dan tekanan darah. Adapun langkah-langkah penelitian yaitu persiapan alat, bahan, melakukan pengukuran berat badan dan pengukuran tekanan darah bagi lansia kemudian mencatat pada lembar observasi, melakukan analisis data yang telah terkumpul. Analisis data dalam penelitian ini menggunakan analisis univariat dan analisis bivariat yaitu uji korelasi spearman.

\section{HASIL}

\section{Karakteristik Responden}

Berdasarkan tabel 1,2, 3, dan 4 diketahui bahwa mayoritas lansia berjenis kelamin perempuan yaitu sebesar 35 responden $(87.5 \%)$, berusia 69 tahun yaitu sebesar 11 responden $(27.5 \%)$, berpendidikan rendah yaitu sebanyak 22 responden $(55 \%)$, dan tidak bekerja yaitu sebanyak 25 responden $(62.5 \%)$.

Tabel 1. Distribusi Frekuensi Berdasarkan Jenis Kelamin

\begin{tabular}{lcr}
\hline \multicolumn{1}{c}{ Jenis Kelamin } & $\mathrm{n}$ & $\mathrm{f}(\%)$ \\
\hline Laki laki & 5 & 12.5 \\
Perempuan & 35 & 87.5 \\
Total & & 100.0 \\
\hline
\end{tabular}

Tabel 2. Distribusi Frekuensi Berdasarkan Usia

\begin{tabular}{ccc}
\hline Usia (tahun) & $\mathrm{n}$ & $\mathrm{f}(\%)$ \\
\hline 60 & 6 & 15.0 \\
61 & 4 & 10.0 \\
62 & 5 & 12.5 \\
64 & 3 & 7.5 \\
65 & 3 & 7.5 \\
66 & 3 & 7.5 \\
67 & 4 & 10.0 \\
68 & 1 & 2.5 \\
69 & 11 & 27.5 \\
Total & 40 & 100.0 \\
\hline
\end{tabular}

Tabel 3. Distribusi Frekuensi Berdasarkan Pendidikan

\begin{tabular}{lcc}
\hline \multicolumn{1}{c}{ Pendidikan } & $\mathrm{n}$ & $\mathrm{f}(\%)$ \\
\hline Rendah & 22 & 55.0 \\
Menengah & 17 & 42.5 \\
Tinggi & 1 & 2.5 \\
Total & 40 & 100.0 \\
\hline
\end{tabular}

Tabel 4. Distribusi Frekuensi Berdasarkan Pekerjaan

\begin{tabular}{lcc}
\hline \multicolumn{1}{c}{ Pekerjaan } & $\mathrm{n}$ & $\mathrm{f}(\%)$ \\
\hline Tidak bekerja & 25 & 62.5 \\
Wiraswasta & 9 & 22.5 \\
Karyawan swasta & 6 & 15.0 \\
Total & 40 & 100.0 \\
\hline
\end{tabular}

\section{Analisis Univariat}

Hasil analisis univariat ditunjukan oleh tabel 5 dan 6. Berdasarkan tabel 5 diketahui bahwa berat badan lansia mayoritas dalam kategori kelebihan berat tingkat berat, yaitu sebanyak $32(80 \%)$. Berdasarkan tabel 6 diketahui bahwa mayoritas tekanan darah lansia dalam kategori hipertensi (HT derajat I-III); yaitu sebanyak $21(52.5 \%)$.

Tabel 5. Distribusi Frekuensi IMT Lansia

\begin{tabular}{|c|c|c|}
\hline IMT & $\mathrm{n}$ & $f(\%)$ \\
\hline $\begin{array}{l}\text { Kelebihan berat tingkat } \\
\text { ringan }\end{array}$ & 8 & 20.0 \\
\hline $\begin{array}{l}\text { Kelebihan berat tingkat } \\
\text { berat }\end{array}$ & 32 & 80.0 \\
\hline Total & 40 & 100.0 \\
\hline
\end{tabular}


Tabel 6. Distribusi Frekuensi Tekanan Darah Lansia

\begin{tabular}{lcc}
\hline \multicolumn{1}{c}{ Tekanan Darah } & $\mathrm{n}$ & $\mathrm{f}(\%)$ \\
\hline Normal (optimal-pre HT) & 19 & 47.5 \\
Hipertensi (HT derajat 1- & 21 & 52.5 \\
III) & & \\
\hline Total & & 100.0 \\
\hline
\end{tabular}

\section{Analisis Bivariat}

Tabel 7. Hasil Uji Korelasi Spearman

\begin{tabular}{rrcc}
\hline Uji korelasi & $\mathrm{N}$ & $\mathrm{r}$ & $\mathrm{p}$ \\
\hline Spearman rank & 40 & 0.401 & 0.010 \\
\hline
\end{tabular}

Analisis bivariat ditunjukan oleh tabel 7 . Diketahui bahwa hasil uji analisis korelasi spearman menunjukan nilai $\mathrm{r}=0.401 \mathrm{dan}$ nilai $\mathrm{p}=0.010$.

\section{PEMBAHASAN}

Pengumpulan data dilakukan pada saat dilaksanakanya posyandu lansia di wilayah setempat pada bulan Januari-Februari 2019. Responden yang hadir kemudian dilakukan penimbangan berat badan dan tinggi badan menggunakan timbangan dan alat pengukur tinggi badan yang telah disiapkan oleh peneliti. Data berat badan dicatat ke dalam lembar observasi. Setelah itu, responden diukur tekanan darahnya menggunakan tensimeter yang telah disiapkan oleh peneliti, kemudian data tekanan darah responden dicatat kedalam lembar observasi. Selain itu ada beberapa data tambahan lainya berupa identitas (karakteristik) responden yang diperoleh melalui wawancara kepada responden.

Perempuan risiko hipertensi akan meningkat setelah masa menopause yang menunjukan adanya pengaruh hormon ${ }^{[4]}$. Begitu juga hasil penelitian ${ }^{[5]}$, menunjukan bahwa jumlah lansia yang memiliki tekanan darah tinggi lebih banyak pada lansia yang berjenis kelamin perempuan, dibandingkan dengan lansia yang berjenis kelamin laki-laki. Beberapa penelitian membuktikan bahwa semakin tinggi umur seseorang maka semakin tinggi tekanan darahnya $^{[6]}$. Semakin tua usia seseorang, akan banyak terjadi penurunan kerja organ tubuh termasuk jantung. Perubahan kardiovaskuler pada lansia yaitu katup jantung menebal, kemampuan memompa darah menurun $1 \%$ tiap tahun yang berakibat pada menurunnya kontraksi dan volume sehingga meningkatkan vasokonstriksi pembuluh darah dan beresiko hiperensi ${ }^{[7]}$. Hal tersebut sesuai dengan $^{[5]}$ yang menyatakan bahwa jika status sosial ekonomi rendah maka arus tekanan darah tinggi menjadi lebih tinggi. Faktor yang berkaitan dengan sosial ekonomi lainya yaitu tingkat Pendidikan. Tingkat pendidikan berhubungan dengan informasi kesehatan yang didapat sehingga dapat mempengaruhi status kesehatan seseorang ${ }^{[8]}$.

Kelebihan gizi pada lansia biasanya berhubungan dengan afluency dan gaya hidup pada usia sekitar 50 tahun. Kondisi ekonomi yang semakin membaik dan tersedianya berbagai makanan saji yang enak dan kaya energi, utamanya dari sumber lemak, terjadi asupan makanan dan zat-zat gizi melebihi kebutuhan tubuh. Gizi yang dimulai pada awal usia 50 tahunan ini akan membawa lansia dalam keadaan obesitas dan dapat pula disertai penyakit metabolisme ${ }^{[9]}$. Usia merupakan faktor resiko hipertensi yang tidak dapat dikontrol, sehingga semakin tua usia maka akan dapat meningkatkan resiko hipertensi, tetapi tekanan darah dapat dikontrol dengan cara farmakologis maupun non farmakologis seperti aktivitas fisik, relaksasi dan menurunkan atau menghindari stressor ${ }^{[10]}$.

Berdasarkan hasil uji korelasi spearman diketahui bahwa terdapat hubungan antara berat badan dan tekanan darah lansia dengan korelasi sedang. Sejalan dengan teori yang menjelaskan bahwa status gizi diatas normal pada wanita yang telah lanjut usia mempunyai dampak yang lebih besar untuk mengalami kejadian hipertensi atau penyakit-penyakit lainnya yang disebabkan melemahnya organ-organ tubuh wanita. Hal ini disebabkan karena adanya peningkatan kadar insulin dan aldosteron dalam plasma 
penderita obesitas. Aldosteron akan mengurangi ekskresi $\mathrm{Na}$ dalam glomeruli, sehingga adanya peningkatan insulin dan aldosteron akan menyebabkan retensi $\mathrm{Na}$ dalam darah yang mengakibatkan terjadinya peningkatan volume darah, sehingga menyebabkan hipertensi ${ }^{[11]}$. Begitu juga menurut American Heart Association $^{[12]}$, IMT diatas 25 terbukti berpengaruh terhadap terjadinya hipertensi. Kelebihan berat badan merupakan faktor resiko yang sering dikaitkan dengan hipertensi. Individu dengan kelebihan berat badan $20 \%$ memiliki risiko 3-8 kali lebih tinggi di banding individu dengan berat badan normal. Orang yang berat badannya berlebih pada umumnya mengalami kesulitan untuk bergerak secara bebas, sedangkan untuk dapat menggerakan tubuhnya, maka jantung harus memompa darah dan membuat tekanan darah naik ${ }^{[13]}$. Hal ini serupa dengan hasil studi ${ }^{[13]}$ yang membuktikan bahwa mereka yang memiliki lemak perut berlebih memiliki peningkatan tekanan darah lebih besar. Kenaikan berat badan, sekitar $2 \mathrm{~kg}$ dapat menempatkan seseorang pada risiko tekanan darah yang meningkat pula ${ }^{[14]}$.

\section{SIMPULAN}

Terdapat hubungan signifikan antara berat badan dengan tekanan darah ditunjukan dengan kekuatan hubungan cukup. Hasil ini ditunjukkan dengan uji korelasi spearman $\mathrm{r}=0.401$ dan nilai $\mathrm{p}=0.010$.

\section{SARAN}

Saran bagi lansia terutama untuk lansia yang berjenis kelamin perempuan diharapkan dapat menjaga berat badanya supaya ideal dengan mengkonsumsi makanan bernutrisi rendah lemak serta diimbangi dengan aktivitas fisik.

\section{DAFTAR PUSTAKA}

1. Potter PA, Perry AG. Fundamentals of Nursing. Jakarta: Salemba medika; 2010; pp: 213, 567-8.
2. Pusdatin. Hipertensi. Jakarta: Departemen Kesehatan; 2014; pp: 2-6.

3. Pusdatin Lansia. Situasi Lanjut usia (Lansia) di Indonesia. Jakarta: Departemen Kesehatan; 2016; pp: 2-4.

4. Triyanto E. Pelayanan Keperawatan bagi Penderita Hipertensi Secara Terpadu. Yogyakarta: Penerbit Andi; 2014; pp: 7, 10-5.

5. Sulistiyowati. Faktor-faktor yang berhubungan dengan hipertensi di kampung botton kalurahan magelang kecamatan magelang tengah kota magelang 2009. Skripsi. https://lib.unnes.ac.id/3205/; 2009

6. Purwanto B. Hipertensi (Pathogenesis, Kerusakan Target Organ dan Penatalaksanaan. Surakarta: UNS Press; 2012; pp: 10-23.

7. Nugroho, Wahyudi. Keperawatan Gerontik, EGC, Jakarta; 2000; diakses tanggal 12 Mei 2019

8. Darmojo, Boedhi. Geriatri (Ilmu Kesehatan Usia Lanjut). Jakarta: Penerbit Fakultas Kedokteran Universitas Indonesia; 2006.

9. Sari AP, Yusuf A, Wahyuni ED. Perubahan Tekanan Darah Lansia dengan hipertensi melalui metode gardening di UPT PSLU Magetan. http://www.journal.unair.ac.id/downlo ad-fullpapers-

cmsnjcfa1cb64a52full.pdf diakses 11 Mei 2019; 2015

10. Hermawan. Komplikasi Obesitas dan Usaha Penanggulangannya. www.kalbe.co.id. Diakses tanggal 14 Januari 2010; 1991.

11. AHA. Small Weight Gain can Raise Blood Pressure in Healthy Adults. http:// news.heart. org/ small- weightgain- can- raise- blood- pressure- inhealthy-adults/ - diakses Mei 2019; 2014

12. Susilo, Ambarwati Y, Wulandari A. Cara Jitu Mengatasi Hipertensi. Yogyakarta: Penerbit Andi; 2011; pp: 22, 41, 56, 57.

13. Mayo Clinic. Does Blood Pressure Have a Daily Pattern? I've Noticed 
That My Blood Pressure Is Always Lower In The Morning Than At Night. http:// www.mayoclinic.org/ diseases-conditions/ high-bloodpressure/expert-answers/ blood- pressure/ faq-20058115 - diakses Mei 2019; 2015.

14. Irianto K. Gizi Seimbang dalam Kesehatan Reproduksi. Bandung: Alfabeta,; 2014. pp: 541-2, 629. 